\title{
INTERMEDIARY ASSET PRICING AND THE FINANCIAL CRISIS
}

\author{
Zhiguo He \\ Arvind Krishnamurthy \\ Working Paper 24415 \\ http://www.nber.org/papers/w24415 \\ NATIONAL BUREAU OF ECONOMIC RESEARCH \\ 1050 Massachusetts Avenue \\ Cambridge, MA 02138 \\ March 2018
}

Prepared for the Annual Review of Financial Economics. We thank Ravi Jagannathan, Wenhao $\mathrm{Li}$, Jiacui Li, Tyler Muir and an anonymous reviewer for comments. Chloe Peng provided excellent research assistance. There are no financial support to acknowledge. The views expressed herein are those of the authors and do not necessarily reflect the views of the National Bureau of Economic Research.

NBER working papers are circulated for discussion and comment purposes. They have not been peer-reviewed or been subject to the review by the NBER Board of Directors that accompanies official NBER publications.

(C) 2018 by Zhiguo He and Arvind Krishnamurthy. All rights reserved. Short sections of text, not to exceed two paragraphs, may be quoted without explicit permission provided that full credit, including (C) notice, is given to the source. 
Intermediary Asset Pricing and the Financial Crisis

Zhiguo He and Arvind Krishnamurthy

NBER Working Paper No. 24415

March 2018

JEL No. E44

\section{ABSTRACT}

"Intermediary asset pricing" understands asset prices and risk premia through the lens of frictions in financial intermediation. Perhaps motivated by phenomena in the financial crisis, intermediary asset pricing has been one of the fastest growing areas of research in finance. This article explains the theory behind intermediary asset pricing and in particular how it is different from other approaches to asset pricing. The article also covers selective empirical evidence in favor of intermediary asset pricing.

\section{Zhiguo He}

University of Chicago

Booth School of Business

5807 S. Woodlawn Avenue

Chicago, IL 60637

and NBER

zhiguo.he@chicagobooth.edu

Arvind Krishnamurthy

Stanford Graduate School of Business

Stanford University

655 Knight Way

Stanford, CA 94305

and NBER

akris@stanford.edu 


\section{Introduction}

This paper aims to introduce a reader to the growing literature on "intermediary asset pricing" that links movements in asset prices and risk premia to frictions in financial intermediation. In classical approaches to asset pricing, as presented in the well-known paper by Fama [1980], intermediaries satisfy the assumptions of the Modigliani-Miller theorem and are a "veil." Asset prices reflect the tastes and shocks of the households who may invest in asset markets through intermediaries, but are the ultimate owners of all assets. However, the performance of many asset markets - e.g., prices of mortgage-backed securities, corporate bonds, derivative securities, etc. - depend on the financial health of the intermediary sector, broadly defined to include traditional commercial banks as well as investment banks and hedge funds. The 2008 financial crisis and the 1998 hedge-fund crisis are two compelling data points in support of this claim. Phenomena in the recent crisis in particular have called into question the veil hypothesis and motivated the study of intermediary asset pricing.

Our article clarifies the theoretical underpinnings of intermediary asset pricing. What does it take to break the veil hypothesis and justify an intermediary pricing kernel? It is commonplace to argue for intermediary asset pricing in certain markets by asserting that because trade is dominated by intermediaries, they must be marginal. But any asset-holder not at a corner in her portfolio choice is marginal. So what is the content of intermediary asset pricing and does intermediary asset pricing refute traditional consumption-based asset pricing? We provides answers to these questions in the first part of the paper, which builds a simple intermediary asset pricing model.

The second part of the paper reviews a small group of papers that are evidence in favor of intermediary asset pricing. The paper review is not exhaustive. Our purpose is to highlight different approaches to testing intermediary asset pricing theories and discuss the advantages and drawbacks of these approaches.

Our paper is an introduction to intermediary asset pricing that can be understood by anyone who has completed the first-year of graduate level work in finance. It is not a comprehensive survey of the area. For a survey on asset market illiquidity and financial 
crises see Amihud et al. [2012]. There are connections between intermediary frictions and macroeconomics that are important and interesting but omitted in this article. Brunnermeier et al. [2013] is a survey of financial frictions and macroeconomic activity. Two influential papers that make the case for intermediary asset pricing are Franklin Allen's 2001 presidential address to the American Finance Association (Allen [2001]) and Darrell Duffie's 2010 presidential address to the same body (Duffie [2010]).

\section{Theory}

The basic ingredients needed to have a well defined model of intermediary asset pricing are as follows: There is an intermediary sector and a household sector. The household sector, or some part of the sector, does not directly invest in some "intermediated" assets. Instead they delegate their investments in these assets to the intermediary sector. Contracting frictions in the intermediary mean that such delegation is not a veil. This leads to a pricing expression for the intermediated assets that depends on intermediary frictions, and drives a wedge between the household and intermediary valuation of assets.

A central assumption is that there is limited participation by the households in a set of assets. This assumption implies that households will not be marginal in pricing these assets. In other words, as we show more formally, their Euler equation will not apply to the pricing of intermediated assets, which opens the door to studying intermediary asset pricing. We can motivate this assumption in two ways. It may be that households lack the knowledge necessary to invest in complex assets (e.g., credit-card asset backed securities) and hence delegate investments to the intermediary. This will be the leading motivation for our article. But, the assumption, albeit in a different form, may also apply in markets that the households have some knowledge, such as the equity market. In these markets, we note that many investors evaluate their consumption and portfolio holdings decisions only infrequently. If households rebalance in a coordinated fashion, say at the end of the tax year, then a standard representative agent consumption CAPM may apply only on these infrequent dates (as documented by Jagannathan and Wang [2007]), but not all dates. ${ }^{1}$ In

\footnotetext{
${ }^{1}$ Jagannathan and Wang [2007] show that the consumption CAPM holds for December-December equity
} 
contrast, since intermediaries are marginal at all dates, intermediary pricing will apply at all dates, with there being a wedge at some dates. The wedge may be higher at some times and for some assets. We clarify these points in the formal model.

Last, as suggested by our motivation of limited participation of households in complex assets markets or annual portfolio rebalancing of households, the intermediary asset pricing phenomena we are concerned with may persist for many months, or even years. Household Euler equations may not apply for long periods of time. We are concerned not with the highfrequency asset price swings of market micro-structure research, but much lower frequency phenomena. The empirical evidence in Section 3 shows this point.

\section{$2.1 \quad$ Model}

We consider a two period $(t=0,1)$ Constant-Absolute-Risk-Aversion (CARA) normal model with only one risky asset. Later we extend the model to the multi-asset case. The

risky asset pays out $\widetilde{D} \sim \mathcal{N}\left(\mu, \sigma^{2}\right)$ per share at date 1 . The exogenous gross interest rate is $1+r$. The aggregate supply of the risky asset is $\theta$.

There is a unit mass of two classes of identical agents: intermediary managers (indicated by $M$ ) and households (indicated by $H$ ). Both agents have CARA preferences over their date-1 wealth. We denote the risk tolerance of managers as $\rho_{M}$ (inverse of the coefficient of absolute risk aversion) and the risk tolerance of households as $\rho_{H}$. Thus, agents maximize the objective

$$
u_{i}\left(W_{1}^{i}\right)=-\exp \left\{-\frac{W_{1}^{i}}{\rho_{i}}\right\},
$$

with $i \in\{H, M\}$ and $W_{1}^{i}$ denoting the end-of-date-1 wealth.

By assumption, the households cannot directly invest in the market for the risky asset at date 0 . For example, the risky asset may be credit-card asset-backed securities which requires specialized knowledge to value. Intermediary managers have the know-how to invest in these assets. This creates scope for intermediation. Households can give some of the wealth to intermediary managers who invest in the risky asset on their behalf. Later, we extend the model to include sophisticated households who are able to invest directly in returns. See also Abel et al. [2013] for a model of infrequent portfolio choices. 
the risky asset and bypass intermediaries.

\subsection{Principal-agent problem}

We assume that intermediation is not frictionless. Following He and Krishnamurthy [2012, 2013], we assume that households can contract with managers to invest on their behalf in the risky asset but subject to a moral hazard friction. Frictions in intermediation are central to intermediary asset pricing and distinguish the approach from models with heterogeneous agents such as Dumas [1989] and Wang [1996] where agents differ in their risk aversion but otherwise trade in markets that are complete and frictionless. We discuss the difference further below.

A manager in an intermediary chooses the quantity of risky assets to buy, $x_{F}$, as well as a due diligence decision when making investments, $s \in\{0,1\}$. If the manager chooses to "shirk," setting $s=0$, the intermediary return falls by $\Delta$ and the manager gains a private benefit of $b$. We can think of shirking as capturing actions such as trading inefficiently in a manner that reduces the fund's return. Throughout our analysis, we assume that parameters are such it is optimal to write a contract that prevents shirking (i.e., shirking is socially costly). Households cannot directly observe the due diligence action and must provide incentives to the manager to not shirk. We assume that households and managers sign an affine contract parameterized by $(K, \phi)$ where $\phi$ is a the linear share of the return generated by the fund that is paid to the manager, and $K$ is a management fee paid by households to managers, which is independent of the fund's return. In general, $K$ will depend on the market protocols according to which households and managers form intermediaries. For example, if this is a search market, then $K$ will be affected by bargaining powers of the parties; while if it is in a Walrasian market, $K$ is set based on the supply of intermediary managers. He and Krishnamurthy [2012, 2013] investigate these different cases. In our CARA setting, the lack of wealth effect implies that the fee $K$ plays no role in asset demands and equilibrium prices. We therefore dispense with $K$, setting it to zero without loss of generality. 
A manager with contract $(\phi)$ solves,

$$
\max _{x_{F}, s \in\{0,1\}}-\exp \left\{-\frac{1}{\rho_{M}}\left[\phi\left(x_{F}(\widetilde{D}-(1+r) p)-s \Delta\right)+s b\right]\right\}
$$

which, since $\widetilde{D}$ is normally distributed, is equivalent to the following standard meanvariance optimization:

$$
\max _{x^{F}, s \in\{0,1\}} \phi\left\{x_{F}[\mu-p(1+r)]-s \Delta\right\}-\frac{x_{F}^{2} \phi^{2} \sigma^{2}}{2 \rho_{M}}+s b .
$$

The first term is the expected excess return on purchasing $x_{F}$ units of the risky asset and receiving a share $\phi$ of this expected return. The asset pays a mean dividend of $\mu$ and is purchased at price $p$. The one period interest rate is $1+r$. If the manager shirks, the fund's return falls by $\Delta$. The second term is the penalty for risk, which is proportional to the variance of the payoff to the risky asset investment, and inversely proportional to $\rho_{M}$, the risk tolerance of the manager. These terms are all familiar from the textbook treatment of portfolio choice in the CARA-normal setting. The last term captures the manager's private benefit from shirking due to moral hazard.

\subsection{Incentive compatibility and equity capital constraint}

This section derives an equity capital constraint that arises from the incentive compatibility constraint in the above contracting problem. The manager's effective holdings of the risky asset when the manager chooses $x_{F}$ and receives a share of the fund's return of $\phi$ is,

$$
x_{M}=\phi x_{F},
$$

while the household's effective holdings are,

$$
x_{H}=x_{F}(1-\phi) .
$$


We can interpret these effective holdings in terms of the financing of an intermediary. The manager and household set up an intermediary with each contributing a fraction of the intermediary's equity capital. For each $\phi$ dollars the manager puts in, the householdinvestor puts in $1-\phi$ dollars; or, equivalently, for each one dollar the manager puts in, the household investors put in $\frac{1-\phi}{\phi}$ dollars. The manager and investors share in the return generated by the intermediary, proportional to their ownership of the equity of the fund.

The incentive compatibility constraint to implement working $(s=0)$ in problem $(1)$ is,

$$
\phi \Delta \geq b \Rightarrow \phi \geq \frac{b}{\Delta}
$$

In words, managers have to own a sufficiently large equity share of the intermediary to retain incentives not to shirk. Define,

$$
m \equiv \frac{1-b / \Delta}{b / \Delta}=\frac{\Delta}{b}-1
$$

Then $m$ is the maximum amount of dollars of outside equity that investors are willing to purchase in an intermediary per dollar of equity that the manager purchases. If $m$ is high (i.e. $b$ is low indicating a small agency friction), the manager can be incentivized with a small $\phi$, i.e., with only a little "skin in the game."

The above discussion implies that we can write the incentive compatibility constraint equivalently as an equity capital constraint,

$$
\phi \geq \frac{1}{1+m}
$$

From now on we will refer to the primitive incentive compatibility constraint as an equity capital constraint.

\subsection{Equilibrium asset price}

We now derive equilibrium asset prices. It useful to first do so in a frictionless economy so as to understand the effect of frictions. Suppose that households could fully participate in 
the risky asset market. Their demand for the risky asset is

$$
x_{H}=\rho_{H} \frac{\mu-p(1+r)}{\sigma^{2}},
$$

and market clearing requires that,

$$
x_{H}+x_{M}=\theta \text {. }
$$

Solving we find that,

$$
p=\frac{\mu}{1+r}-\frac{1}{\rho_{H}+\rho_{M}} \cdot \frac{\theta \sigma^{2}}{1+r} .
$$

In our model with frictions, given the equity fraction $\phi$ to be determined endogenously shortly, the optimal portfolio solution $x_{F}$ to the manager's problem in (1) satisfies (recall Eq. (2)),

$$
\phi x_{F}=x_{M}=\rho_{M} \frac{\mu-p(1+r)}{\sigma^{2}} .
$$

Given this choice of $x_{M}$, the household's effective (i.e. via his investment in the intermediary) holding of the risky asset is

$$
x_{H}=x_{F}(1-\phi)=\frac{1-\phi}{\phi} \rho_{M} \frac{\mu-p(1+r)}{\sigma^{2}} .
$$

And the same market clearing condition implies that

$$
p=\frac{\mu}{1+r}-\frac{\phi}{\rho_{M}} \cdot \frac{\theta \sigma^{2}}{1+r} .
$$

Comparing (9) with (6), we see that the frictionless economy requires an equity share of

$$
\phi=\frac{\rho_{M}}{\rho_{M}+\rho_{H}} .
$$

This is intuitive. In the frictionless benchmark, each agent group owns risky asset according to their risk tolerances, with managers owning $\frac{\rho_{M}}{\rho_{M}+\rho_{H}}$ of the risky asset. In the equilibrium of frictionless benchmark, both agents' risk tolerance parameters determine the asset price 
as in Equation (6).

To understand the impact of the frictions, suppose that $\rho_{M}$ is low relative to $\rho_{H}$; in other words, managers are relatively risk averse. Then, with moral hazard, we see that the frictionless equity share may violate the equity constraint in (5),

$$
\phi=\frac{\rho_{M}}{\rho_{M}+\rho_{H}} \geq \frac{1}{1+m}
$$

That is, the frictionless risk allocation may not be achievable given the incentive compatibility constraint implied by the moral hazard friction. Rearranging, we say that when

$$
m \geq \frac{\rho_{H}}{\rho_{M}}
$$

intermediation is a veil. When this condition is violated, intermediation is not a veil and intermediary financing frictions affect asset prices. These results are summarized in the following Proposition.

Proposition 1 The equilibrium asset price, $p$, solves:

$$
p=\left\{\begin{array}{cc}
\frac{\mu}{1+r}-\frac{\theta \sigma^{2}}{(1+r)(1+m) \rho_{M}} & \text { if } m=\frac{\Delta}{b}-1 \leq \frac{\rho_{H}}{\rho_{M}} \\
\frac{\mu}{1+r}-\frac{\theta \sigma^{2}}{(1+r)\left(\rho_{M}+\rho_{H}\right)} & \text { otherwise }
\end{array}\right.
$$

Here, the first term, $\frac{\mu}{1+r}$ is the expected value of the asset. The second term is the risk discount which is proportional to asset supply, $\theta$, and risk, $\sigma^{2}$. From the first line, we see that when $m$ is small, intermediary frictions are tight and the risk discount is large and increasing in the intermediary frictions (i.e., falling $m$ ). From the second line, we see that when $m$ is large enough, intermediary frictions do not affect prices.

\subsection{Intermediation shocks}

In the world, shocks to intermediation may affect asset prices. Such shocks can be decreases in intermediary capital caused by losses or investor withdrawals or increases in the complexity of intermediary investments which increase the moral hazard friction. There 
is considerable empirical evidence (which we review in Section 3) that such effects were present in the financial crisis. Indeed, the model implies that shocks to intermediation should especially affect asset prices during financial crises. To see this, take the case of an increase in moral hazard, corresponding to a decrease in $m$. During the crisis, given the complexity of investment environment it is likely that delegation became harder, increasing $b$ and hence decreasing $m$. A decrease in $m$ lowers the risk asset price $p$ only if $m \leq \frac{\rho_{H}}{\rho_{M}}$ so that equity constraint binds. When $m$ is high (i.e., $b$ is small) so that $m>\frac{\rho_{H}}{\rho_{M}}$, changes in $m$ have no effect on $p$. This non-linearity is a central feature of the intermediary asset pricing model of He and Krishnamurthy $[2012,2013] .{ }^{2}$ Indeed it is one clear distinction between the intermediary pricing model and the two-agent model of Dumas [1989]. From Proposition 1 when $m$ is very large (no frictions) we see that the asset price reflects the average risk tolerance of agents in the economy. In a two-agent model such as Dumas [1989] this average risk tolerance is a function of the relative wealth of the two agents in the economy, which is a slow-moving state variable. There is no notion of a constraint so that the mechanism linking relative wealth and asset returns works in the same manner throughout the state space, rather than particularly sharply in some parts of the state space. Thus, this approach does not lead to the non-linearity which is evidently a feature of financial crises. Additionally, phenomena such as increases in moral hazard or complexity of assets play no role in such a model.

He and Krishnamurthy [2012, 2013] show that shocks to the manager's wealth, which can be interpreted as capital shocks, impact asset prices in a non-linear fashion. Capital shocks have no role in the present analysis because agents have CARA utility and wealth effects are absent. In a Constant-Relative-Risk-Aversion (CRRA) preference model we will have such effects, and we can see how such effects work by considering a local approximation. The agent's absolute risk aversion, $\frac{1}{\rho_{M}}$, is related to the coefficient of relative risk aversion,

${ }^{2}$ Models such as Allen and Gale [1994] which mix segmentation and cash-in-the-market pricing deliver the non-linearity and have been useful frameworks to understand financial crises (see Allen and Gale [1998]). But these models do not connect to the empirical asset pricing evidence we discuss in Section 4 . In particular, the evidence regards variation in the cross-section of asset returns and ties such variation to an intermediary stochastic discount factor. Under the cash-in-the-market pricing model of Allen and Gale [1994], there is no variation in the cross-section of expected returns across intermediated assets. 
$\gamma$, via wealth:

$$
\frac{1}{\rho_{M}}=\frac{\gamma}{W_{M}} .
$$

A fall in $W_{M}$ translates to a fall in $\rho_{M}$. Then from our analysis of the CARA model, such a change will lead the equilibrium asset price $p$ to fall. While this wealth effect will be present both when intermediation is constrained and when it is not, the effect is larger when intermediation is constrained.

More formally, we can see the wealth effects as follows. When the equity constraint binds, the Sharpe ratio of the asset, denoted by $S R$, is given by

$$
S R=\frac{\mathbb{E}[(\widetilde{D}-p) / p]-r}{S t d((\widetilde{D}-p) / p)}=\frac{\mu / p-1-r}{\sigma / p}=\frac{\mu-p(1+r)}{\sigma}=\frac{\theta \sigma}{(1+m) \rho_{M}} .
$$

In fact, we can relate the Sharpe ratio to the coefficient of relative risk aversion as,

$$
\begin{aligned}
S R & =\underbrace{{\text { Std. Dev. of Dollar Return of } W_{1, M}=\theta \widetilde{D} /(1+m)}_{\rho_{M}}^{\frac{1}{\rho_{M}}}}_{\text {Absolute Risk Aversion }} \underbrace{\frac{1}{\rho_{M}} W_{0 . M}}_{\text {Relative Risk Aversion }} \underbrace{\frac{\theta \sigma}{W_{0, I}}}_{\text {Std. Dev. of Percentage Ret. of } \frac{W_{1, I}}{W_{0, I}}}=\frac{1}{\rho_{M}} W_{0, M} \cdot \frac{\sigma}{p}
\end{aligned}
$$

Here $W_{0, M}$ represents the date 0 wealth of the manager, which is invested in the equity of the intermediary, and $W_{0, I}$ is the date 0 total capital of the intermediary, which is equal to $W_{0, M}(1+m)$ when the equity constraint binds. The date- 0 capital of the intermediary is $W_{0, I}=\theta p$, since the intermediary purchases all of the risky asset. The second equation clarifies that the price of risk is the coefficient of relative risk aversion of the marginal agent, multiplied by the volatility of the marginal agent's wealth return.

\subsection{Regulatory capital}

In practice, financial intermediaries face regulatory capital constraints that may affect their demand for assets and impact asset prices. The effects of these type of constraints are similar to the wealth effects we have discussed. Whether or not they affect asset prices 
depends on financing frictions and whether intermediaries are a veil. The effects of shocks to capital are non-linear and depend on whether or not capital constraints bind. ${ }^{3}$

To see these points, we extend our model. We have noted that the key incentive compatibility constraint (4) of the model can be interpreted in terms of the equity financing of an intermediary. The manager and household set up an intermediary by each contributing a fraction of the intermediary's capital. For each one dollar the manager puts in, the household investors put in at most $m=\frac{1-\phi}{\phi}$ dollars, so that the manager's equity share $\phi$ never falls below $1 /(1+m)$ as in $(5)$.

Suppose that a manager has wealth of $W_{M}$ with which he invests in the intermediary as equity. The total equity capital of an intermediary is $E_{F}$, subject to the equity constraint derived above,

$$
E_{F} \leq W_{M}(1+m)
$$

Suppose an intermediary purchases the risky asset and makes some commercial loans of $L$ to an unmodeled corporate sector. The portfolio is subject to a regulatory capital constraint,

$$
k_{x} \cdot p x_{F}+k_{L} \cdot x_{L} \leq E_{F}
$$

where $k_{x}$ and $k_{L}$ correspond to the capital charges on the risky asset and on loans in the spirit of Basel risk-based capital requirements. ${ }^{4}$ Denote the Lagrange multiplier on (14) by $\lambda_{R C} \geq 0$.

Putting these two constraints in (13) and (14) together, we have

$$
\underset{\text { regulatory capital constraint }}{k_{x} \cdot p x_{F}+k_{L} x_{L} \leq} E_{F} \underset{\text { equity capital constraint }}{\leq} W_{M}(1+m)
$$

It is important to note that the capital requirement binds (i.e., the first inequality in

\footnotetext{
${ }^{3}$ It should be evident that the two-agent approach of, e.g., Dumas [1989], cannot speak to these regulatory capital effects. If an intermediaryâĂŹs regulatory capital constraint binds, but intermediation is frictionless so the Modigliani-Miller theorem applies, the intermediary would raise more equity capital and adjust its capital structure so that the constraint is slack.

${ }^{4}$ One can think of the regulator as a principal, who, like the household, has a payoff that is tied to the manager's portfolio decisions. For example, the regulator may be concerned with a default externality and hence wants to limit intermediary risk and leverage. Then the regulatory constraint is also an incentive compatibility constraint on the manager, that can be loosened if the manager has more equity capital.
} 
(15)) only if the equity constraint binds (i.e., the second inequality in (15)). In other words, $\lambda_{R C}>0$ only when $\phi=\frac{1}{1+m}$ so that the equity constraint (5) binds. If the equity constraint remains slack, then intermediaries can raise equity capital from households to fund the investment in the risky asset, and households are willing to do so as long as the delegated investment in the risky asset is profitable. As a result, if the equity constraint is slack, no constraints will bind and we will again find that intermediation is a veil.

The manager of the intermediary chooses holdings of the risky asset to maximize his objective subject to (14). The optimization over $x_{F}$ is, ${ }^{5}$

$$
\max _{x_{F}} x_{F}(\mu-p(1+r))-\frac{\phi \sigma^{2}}{2 \rho_{M}} x_{F}^{2}-\lambda_{R C} \cdot k_{x} \cdot x_{F} p
$$

Recall $\lambda_{R C} \geq 0$ is the Lagrange multiplier on the capital constraint, (14), i.e., the return on equity of the intermediary. By purchasing a unit of the risky asset, if the constraint already binds, then the intermediary needs to scale back a profitable loan to free-up regulatory capital by $k_{x} \cdot x_{F} p$.

This optimization problem gives,

$$
\mu-p(1+r)-\frac{\phi \sigma^{2}}{\rho_{M}} x_{F}-\lambda_{R C} k_{x} p=0 \Rightarrow x_{F}=\frac{\rho_{M}}{\phi \sigma^{2}}\left[\mu-p\left(1+r+\lambda_{R C} k_{x}\right)\right]
$$

Imposing market clearing, we find the equilibrium price,

$$
p=\frac{\mu}{1+r+\lambda_{R C} k_{x}}-\frac{\phi \sigma^{2} \theta}{\left(1+r+\lambda_{R C} k_{x}\right) \rho_{M}}
$$

where $\phi=\frac{1}{1+m}$ when (5) binds, and $\frac{\rho_{H}}{\rho_{H}+\rho_{M}}$ otherwise.

The supplementary leverage ratio requirement (SLR), which is not risk-based, corresponds to a requirement where $k_{x}\left(=k_{L}\right)$ is constant and independent of asset characteristics. We see that in this case a tighter capital constraint (a higher $\lambda_{R C}$ ) amounts to an increase of the discount rate on the risky asset.

In the case of a risk-based capital requirement, $k_{x}$ is proportional to risk, i.e. $k_{x}=k \times \sigma$

\footnotetext{
${ }^{5}$ We are suppressing the optimization over $x_{L}$ as it only plays a role in our analysis via its influence on $\lambda_{R C}$.
} 
for some positive constant $k>0$. For relatively small $\sigma$, the price expression allows for the following approximation

$$
p \approx\left(1-\lambda_{R C} k \sigma\right)\left(\frac{\mu}{1+r}-\frac{\phi \sigma^{2} \theta}{(1+r) \rho_{M}}\right)
$$

so that the equilibrium asset price reflects an additional compensation for risk.

Finally, we have shown that the equilibrium price is affected by the capital requirement $\left(\lambda_{R C}>0\right)$ only if the equity capital constraint binds. Moreover, as the Lagrange multiplier $\lambda_{R C}$ on the regulatory capital constraint should increase with losses in equity capital $E_{F}$, the model extension with regulatory capital also implies non-linear effects of shocks to capital for asset prices.

\subsection{Multiple assets and households}

We return to the basic model without the regulatory capital constraint, and instead introduce a second asset into the model; it is straighforward to generalize to $N$ assets. Asset $j \in\{1,2\}$ has date-1 risky payoff $\widetilde{D}_{j} \sim \mathcal{N}\left(\mu_{j}, \sigma_{j}^{2}\right)$. For simplicity, we assume that $\operatorname{Cov}\left(\widetilde{D}_{1}, \widetilde{D}_{2}\right)=0$. We assume that households can participate in asset market 2 but must go through intermediaries to invest in asset market 1 . For example, asset market 1 is credit card asset-backed securities and asset market 2 is the S\&P500 index. Mapping to our model which puts underlying agency fictions at the asset level, another equivalent interpretation is that asset 1, potentially due to its sophisticated nature, has a relatively high agency friction $b_{1}$ which gives rise to a low $m_{1}$, while there is much less (or zero) agency friction in asset 2 (and hence an arbitrary high $m_{2}$ ).

We also introduce a third class of agents, sophisticated households, who have CARA utility with risk tolerance $\rho_{S}$. We assume these households can fully participate in all asset markets, but unlike managers they cannot set up intermediaries. Denote the demand of asset $j \in\{1,2\}$ by agent $i \in\{H, S, M\}$ as $x_{i}^{j}$.

In our CARA-Normal framework, independent payoff distributions imply independent demand system for each asset, and one can easily derive the equilibrium asset prices as presented in the following proposition. More importantly, the comparative statics results 
with respect to $m$, capital, and the non-linear effects we have described continue to hold in the equilibrium with two assets.

Proposition 2 Suppose that the intermediation constraint binds, i.e., $m_{1}<\frac{\rho_{H}}{\rho_{M}}$, then asset market equilibrium is:

$$
\begin{aligned}
& p_{1}=\frac{\mu_{1}}{1+r}-\frac{\theta_{1} \sigma_{1}^{2}}{(1+r)\left[\left(1+m_{1}\right) \rho_{M}+\rho_{S}\right]} \\
& p_{2}=\frac{\mu_{2}}{1+r}-\frac{\theta_{2} \sigma_{2}^{2}}{(1+r)\left(\rho_{S}+\rho_{H}+\rho_{M}\right)} .
\end{aligned}
$$

The two asset case illustrates one approach to testing intermediary asset pricing. Suppose that we have two similar assets, one of which is intermediated (asset 1) and one which

is not (asset 2); and we construct the spread $p_{1}-p_{2}$. Suppose further that one can credibly identify a shock that increases intermediation frictions (decrease in $m_{1}$ or $\rho_{M}$ ). Then, the spread $p_{1}-p_{2}$ should rise after this shock. This difference-in-difference strategy has been employed in a number of empirical papers documenting intermediary asset pricing effects in the crisis. We discuss some of these papers in Section 3.

\subsection{Degree of intermediation}

We next describe how assets that are more intermediated will be affected by intermediary frictions. Suppose that the mass of the sophisticated households is $S$. We have derived price expressions for the case of $S=1$, but it is straightforward to generalize the formulae. When the intermediary constraint binds, the risk premium on asset 1 which is denoted by $\Pi_{1}\left(m_{1}, \theta_{1}, S\right)$ is:

$$
\Pi_{1}\left(m_{1}, \theta_{1}, S\right)=\mu_{1}-(1+r) p_{1}=\frac{\theta_{1} \sigma_{1}^{2}}{\left(1+m_{1}\right) \rho_{M}+S \rho_{S}}
$$

which depends on the agency parameter $m_{1}=\frac{\Delta}{b_{1}}-1$. As noted, an increase in $m_{1}$ reduces the intermediation friction, which reduces the risk premium:

$$
\frac{\partial \Pi_{1}\left(m_{1}, \theta_{1}, S\right)}{\partial m_{1}}=-\frac{\theta_{1} \sigma_{1}^{2} \rho_{M}}{\left[\left(1+m_{1}\right) \rho_{M}+S \rho_{S}\right]^{2}}<0 .
$$


We highlight a further comparative static. Asset 1 is held by both intermediaries and sophisticated households. We will say the asset is more intermediated if the share held by intermediaries is higher, and we vary $S$ to illustrate the effect. A larger $S$ means that more sophisticated households hold asset 1, which implies that intermediaries hold less of the asset. Then we have

$$
\frac{\partial^{2} \Pi_{1}\left(m_{1}, \theta_{1}, S\right)}{\partial m_{1} \partial S}=\frac{2 \theta_{1} \sigma_{1}^{2} \rho_{M} \rho_{S}}{\left[\left(1+m_{1}\right) \rho_{M}+S \rho_{S}\right]^{3}}>0
$$

As $S$ rises (less intermediated asset), the sensitivity of the asset premium to the intermediation friction $\frac{\partial \Pi_{1}\left(m_{1}, \theta_{1}, S\right)}{\partial m_{1}}$, which is negative, is dampened.

As an example, both intermediaries and sophisticated households trade equities. But, intermediaries are a more significant player in the equity options market than the equity market. Thus, we would expect to see that a shock to intermediation would have a larger impact on equity options than equities. As the next section illustrates, this translates to a higher beta for equity options than equities, all else equal.

\section{$2.9 \quad$ Euler equation tests}

We next show that one can use the first-order-conditions of the agents to express the expected return on asset $j$ in the standard $\lambda \beta_{j}$ form, where $\lambda$ is the price of risk associated with a risk factor and $\beta_{j}$ is the loading of asset- $j$ on the risk factor. A number of papers in the empirical literature construct an intermediary stochastic discount factor (SDF) and show that this factor successfully prices asset returns. Our analysis clarifies the manner in which these papers test intermediary asset pricing theory.

The intermediary managers are marginal investors in both asset 1 and asset 2 so that their Euler equations will hold for both assets. Managers hold $\frac{\rho_{M} \theta_{1}}{\left(1+m_{1}\right) \rho_{M}+\rho_{S}}$ share of asset 1 and $\frac{\rho_{M} \theta_{2}}{\rho_{S}+\rho_{H}+\rho_{M}}$ shares of asset 2. The dollar variance of their wealth is (recall both asset payoffs are uncorrelated):

$$
\operatorname{Var}\left(\widetilde{W}_{1 M}\right)=\frac{\rho_{M}^{2} \theta_{1}^{2} \sigma_{1}^{2}}{\left[\left(1+m_{1}\right) \rho_{M}+\rho_{S}\right]^{2}}+\frac{\rho_{M}^{2} \theta_{2}^{2} \sigma_{2}^{2}}{\left(\rho_{S}+\rho_{H}+\rho_{M}\right)^{2}}
$$


The beta of each asset with respect to the manager's wealth is

$$
\begin{aligned}
& \beta_{1}=\frac{\operatorname{Cov}\left(\widetilde{W}_{1 M}, \widetilde{D}_{1}\right)}{\operatorname{Var}\left(\widetilde{W}_{1 M}\right)}=\frac{\frac{\rho_{M} \theta_{1} \sigma_{1}^{2}}{\left(1+m_{1}\right) \rho_{M}+\rho_{S}}}{\frac{\rho_{M}^{2} \theta_{1}^{2} \sigma_{1}^{2}}{\left[\left(1+m_{1}\right) \rho_{M}+\rho_{S}\right]^{2}}+\frac{\rho_{M}^{2} \theta_{2}^{2} \sigma_{2}^{2}}{\left(\rho_{S}+\rho_{H}+\rho_{M}\right)^{2}}}, \\
& \beta_{2}=\frac{\operatorname{Cov}\left(\widetilde{W}_{1 M}, \widetilde{D}_{2}\right)}{\operatorname{Var}\left(\widetilde{W}_{1 M}\right)}=\frac{\frac{\rho_{M} \theta_{2} \sigma_{2}^{2}}{\rho_{S}+\rho_{H}+\rho_{M}}}{\frac{\rho_{M}^{2} \theta_{1}^{2} \sigma_{1}^{2}}{\left[\left(1+m_{1}\right) \rho_{M}+\rho_{S}\right]^{2}}+\frac{\rho_{M}^{2} \theta_{2}^{2} \sigma_{2}^{2}}{\left(\rho_{S}+\rho_{H}+\rho_{M}\right)^{2}}} .
\end{aligned}
$$

We can then write the risk premium of asset 1 as,

$$
\begin{aligned}
\mu_{1}-(1+r) p_{1} & =\frac{\theta_{1} \sigma_{1}^{2}}{\left(1+m_{1}\right) \rho_{M}+\rho_{S}} \\
& =\underbrace{\frac{1}{\rho_{M}} \underbrace{\frac{\rho_{M}^{2} \theta_{1}^{2} \sigma_{1}^{2}}{\left[\left(1+m_{1}\right) \rho_{M}+\rho_{S}\right]^{2}}+\frac{\rho_{M}^{2} \theta_{2}^{2} \sigma_{2}^{2}}{\left(\rho_{S}+\rho_{H}+\rho_{M}\right)^{2}}}_{\text {Variance of Manager Wealth }} \underbrace{\frac{\rho_{M}^{2} \theta_{2}^{2} \sigma_{2}^{2}}{\left(\rho_{S}+\rho_{H}+\rho_{M}\right)^{2}}}_{\beta_{1}^{M} \frac{\rho_{M}^{2} \theta_{1}^{2} \sigma_{1}^{2}}{\frac{\rho_{M} \theta_{1} \sigma_{1}^{2}}{\left(1+m_{1}\right) \rho_{M}+\rho_{S}}}}}_{\lambda_{M}}
\end{aligned}
$$

and the risk premium for asset 2 is,

$$
\begin{aligned}
& \mu_{2}-(1+r) p_{2}=\frac{\theta_{2} \sigma_{2}^{2}}{\rho_{S}+\rho_{H}+\rho_{M}}
\end{aligned}
$$

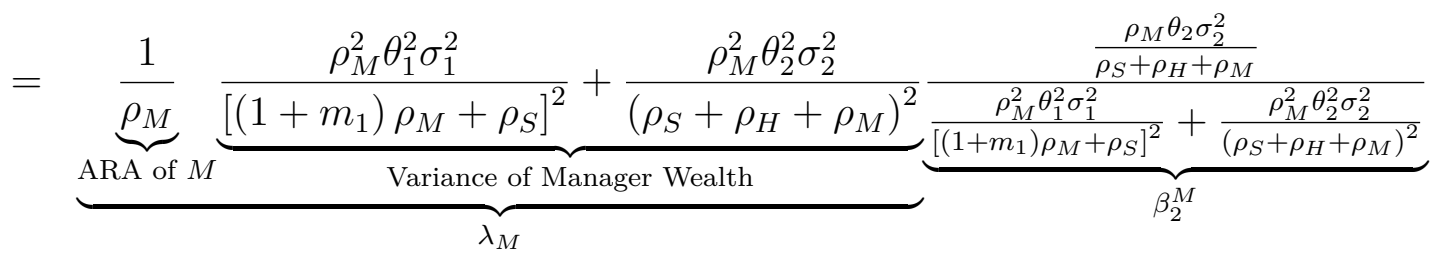

These expressions are intuitive. The risk premium is proportional to the inverse of the risk tolerance of the manager $\left(\frac{1}{\rho_{M}}\right)$, the variance of the manager's wealth, and the beta of asset- $j\left(\beta_{j}^{M}\right)$ with respect to the manager's wealth. That is, a CAPM holds with the manager's wealth as the market factor, with the price of risk being denoted by $\lambda_{M}$ in the above expressions.

What is the content of tests of an "intermediary SDF"? We see from these formulae that an intermediary SDF should price all assets. But this will be true whether or not intermediary constraints bind. The real bite of these tests is in $\beta_{1}^{M}$ versus $\beta_{2}^{M}$. Comparing the numerators of the beta expressions, we see that a binding intermediary constraint 
increases $\beta_{1}^{M}$ relative to $\beta_{2}^{M}$. That is, all else equal, more intermediated assets should have a higher beta with respect to the intermediary factor than non-intermediated assets. These effects are increasing in the strength of intermediary frictions (i.e., as $m_{1}$ falls, $\beta_{1}^{M}$ rises).

Next consider the pricing expressions for sophisticated households. These households trade both asset 1 and asset 2 , and we should expect that a $\lambda \beta_{j}$-pricing formula similar to the intermediary one should apply in this case as well, but with sophisticated household wealth as the market factor. After some algebra, we find:

$$
\begin{aligned}
& \mu_{1}-(1+r) p_{1}=\frac{\theta_{1} \sigma_{1}^{2}}{\left(1+m_{1}\right) \rho_{M}+\rho_{S}}
\end{aligned}
$$

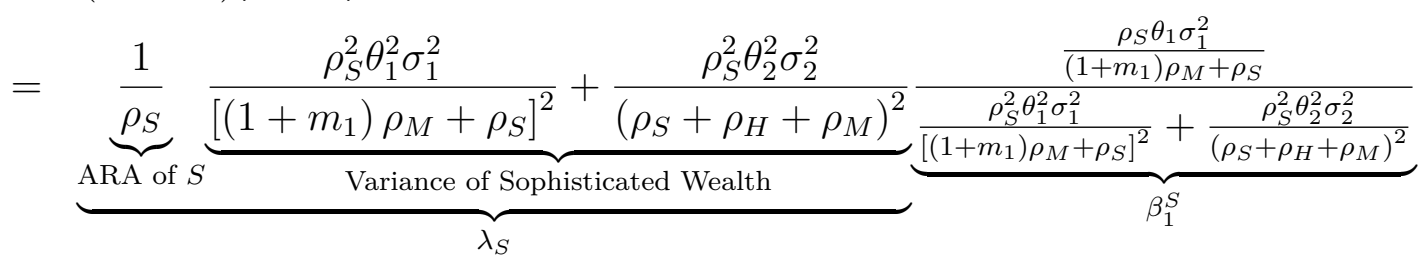

$$
\begin{aligned}
& \mu_{2}-(1+r) p_{2}=\frac{\theta_{2} \sigma_{2}^{2}}{\rho_{S}+\rho_{H}+\rho_{M}}
\end{aligned}
$$

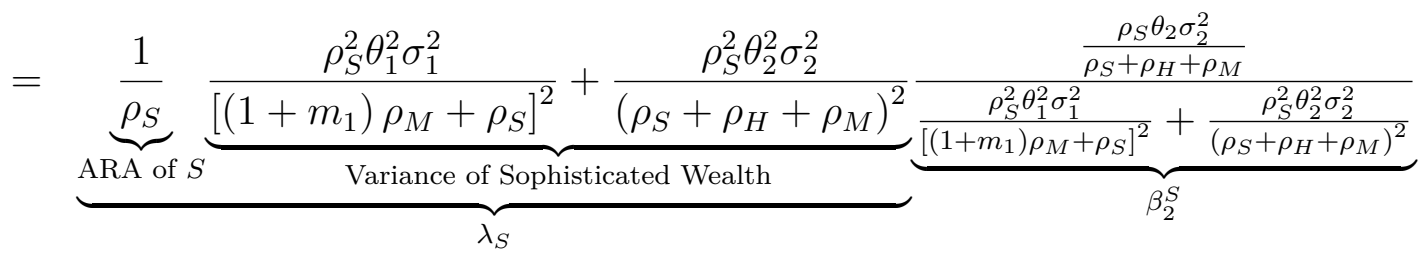

The sophisticated households' wealth also successfully prices both assets, with a price of risk given by $\lambda_{S}$, and loadings, $\beta_{1}^{S}$ and $\beta_{2}^{S}$.

Last consider the households who delegate investments in asset 1 to the intermediary, 
but invest in asset 2 directly. We have

$$
\begin{aligned}
& \mu_{1}-(1+r) p_{1}=\frac{\theta_{1} \sigma_{1}^{2}}{\left(1+m_{1}\right) \rho_{M}+\rho_{S}}
\end{aligned}
$$

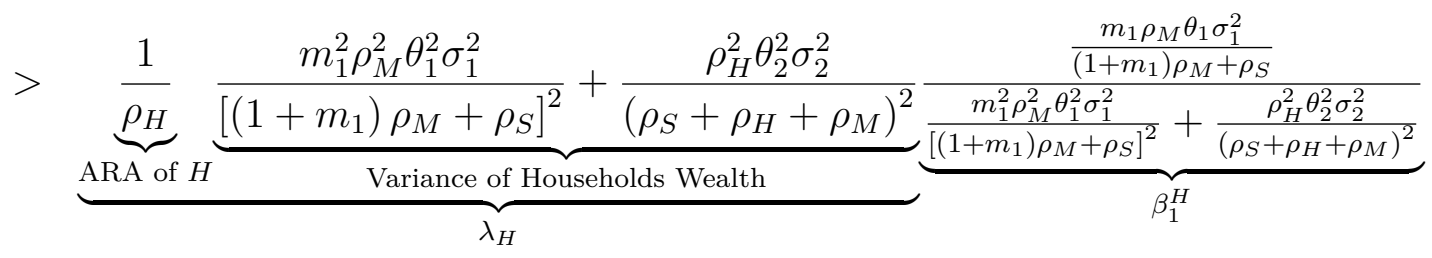

$$
\begin{aligned}
& \mu_{2}-(1+r) p_{2}=\frac{\theta_{2} \sigma_{2}^{2}}{\rho_{S}+\rho_{H}+\rho_{M}}
\end{aligned}
$$

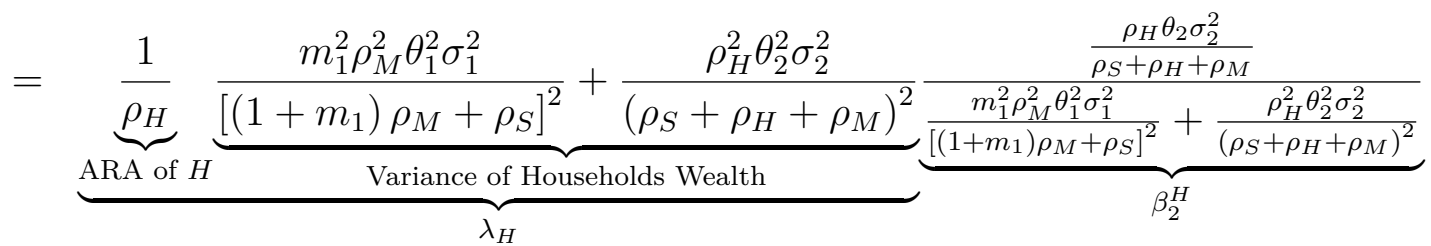

These agents' wealth prices asset 2 , but not asset 1 . This is simply because their investments in asset 1 is constrained by the intermediary friction, i.e., households are not marginal in the asset 1 market. Indeed, the households' pricing expression for asset 1 is an inequality, reflecting the limited participation constraint.

The fact that the pricing expression for asset 1 is an inequality, while that of asset 2 holds with equality, offers a further prediction of intermediary asset pricing:

$$
\frac{\beta_{1}^{M}}{\beta_{2}^{M}}>\frac{\beta_{1}^{H}}{\beta_{2}^{H}} .
$$

Relative to the beta for asset 2, the intermediated asset will have a higher beta with respect to intermediary wealth than with respect to household wealth. Moreover, this differential should increase with intermediary frictions (lower $m$ ). These testable implications are developed and evaluated in a recent paper by Haddad and Muir [2017], who explore the dependence of the heterogeneous sensitivity across asset classes on households' direct participation costs.

Our analysis lead us to a number of conclusions:

\section{Proposition 3}

1. An intermediary based pricing factor will price the cross-section of asset returns 
whether or not intermediaries are a veil. Empirical results demonstrating the success of an intermediary factor are necessary but not sufficient conditions for frictional intermediary based asset pricing theories.

2. A sophisticated household based pricing factor will price the cross-section of asset returns whether or not there are intermediary frictions. Such frictions would only affect the betas.

3. A sufficient condition for rejecting intermediary based asset pricing is that the Euler equations for the households who delegate their funds to the intermediary prices the intermediated assets.

This last point is a key one for SDF-type tests of intermediary asset pricing. Intermediary asset pricing requires that an intermediary SDF prices returns and the household SDF fails to price returns. Note that testing intermediary asset pricing involves a joint hypothesis problem. We need to specify the SDF of the households, so that the test is a joint one of a household and intermediary SDF.

\section{Empirically Connecting Capital Shocks to Asset Price Changes}

The financial crisis has provided a number of data points in support of intermediary asset pricing theories. During the crisis, intermediaries suffered losses to their capital. In terms of the model, $m$ fell. The returns on assets that are commonly associated with intermediary trading rose. See Krishnamurthy [2010] and Mitchell and Pulvino [2012], who document these phenomena in a number of asset markets.

Figure 1 is from Krishnamurthy [2010]. It graphs the option-adjusted spreads on GNMA mortgage-backed securities, a security which was at the heart of the financial crisis, over a period from 2007 to 2009. Spreads rise in the crisis in 2008 coinciding with intermediaries suffering losses to their capital. As the crisis abates in 2009 and as banks raise equity capital from the U.S. government and public equity markets, the spreads fall. 


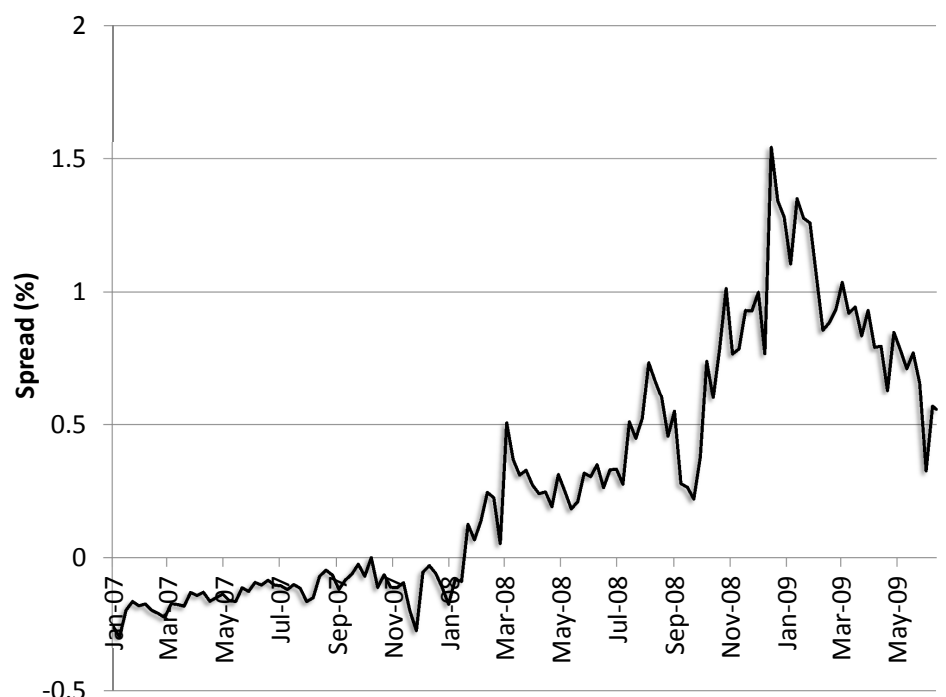

Figure 1: This figure graphs the option-adjusted spreads on GNMA mortgage-backed securities relative to swap rates. The spreads are highest at the depths of the crisis in late 2008 and early 2009. Source: Krishnamurthy [2010].

Figure 2 considers a 2005 episode of a dislocation in the convertible bond market. The figure is from Mitchell et al. [2007]. The left panel plots the quantity of assets of three types of financial intermediaries, convertible bond arbitrage hedge funds, multi-strategy hedge funds and convertible bond mutual funds. Convertible bond arbitrage hedge funds specialize in purchasing convertible bonds, hedging out the equity risk, and capturing a return when such a hedged strategy is profitable. In 2004, there were withdrawals from these hedge funds which resulted in a substantial fall in the capital available for trading by these funds. Related funds such as convertible bond mutual funds or multi-strategy hedge funds did not see similar redemptions. The capital reductions were matched by a reduction in the prices of convertible bonds and increases in returns on convertible bonds, as pictured on the right panel of the figure.

Figure 1 and 2 are good examples of the intermediary asset pricing phenomena this paper is concerned with. The disruption in intermediation is associated with movements in the prices of intermediated asset classes. The price movements reverse over the course of months, not the minutes or days that is the province of research in market micro- 

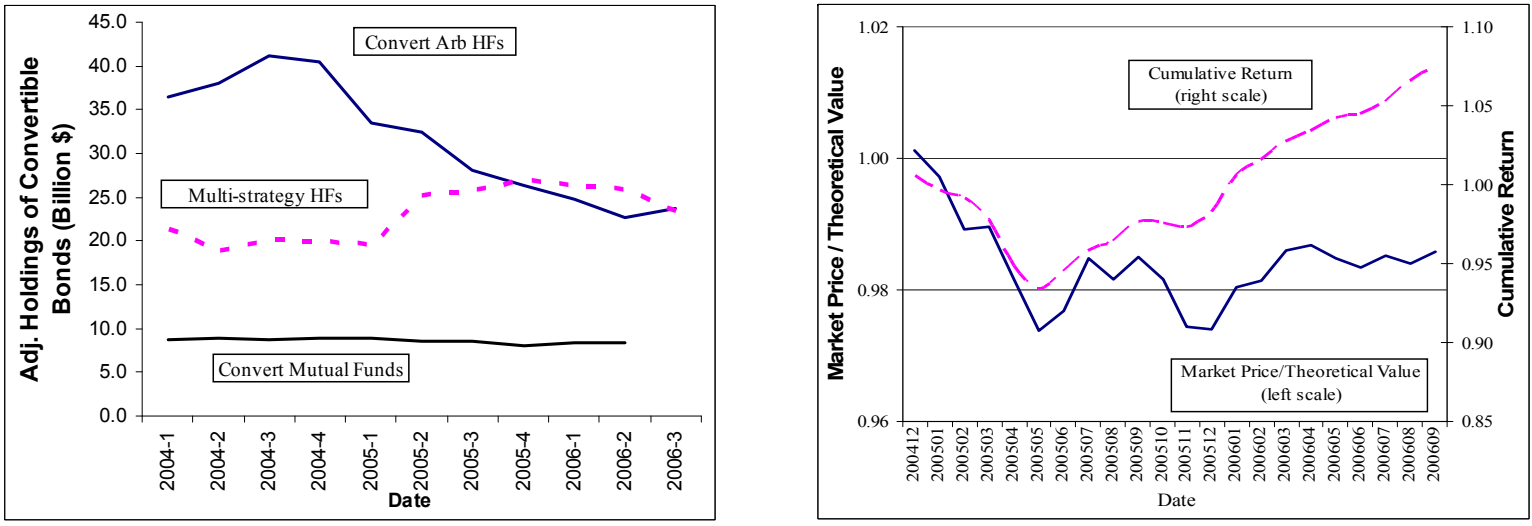

Figure 2: The left panel graphs the quantity of holdings of three types of bond intermediaries. The right panel graphs the returns on convertible bonds as well as the a model-based metric of price to fundamental value of convertible bonds. Source: Mitchell et al. [2007].

structures. The phenomena reflect "slow-moving" intermediary capital in the language of Darrell Duffie's presidential address to the American Finance Association (Duffie [2010]).

However, these figures are not conclusive. Suppose intermediation is a veil and suppose that a shock increased the risk premium households demand for holding mortgage risk (or convertible bond risk). In this case we will see a reduction in the prices of mortgage bonds (convertible bonds), losses to intermediaries specializing in these types of assets, and subsequently higher returns to these bonds. This type of problem is a challenge for many empirical studies of intermediary asset pricing. The rest of this section describes empirical experiments which solve this identification problem.

\subsection{CIP deviation}

The failure of covered interest parity (CIP) is one of the most glaring asset pricing anomalies in the crisis. Consider two trades.

- Trade A: Convert one US Dollar into Euros at time $t$ at exchange rate $S_{t}$. Invest the funds in the Euro market at a riskless interest rate $i_{t}^{\text {Euro }}$ for a term of one period to receive $S_{t}\left(1+i_{t}^{\text {Euro }}\right)$ Euros at $t+1$. Simultaneously purchase a forward contract at price $F_{t}$ from a financial intermediary that converts $F_{t}$ Euros into one US Dollar. By 
striking this forward, the payoff at $t+1$ in dollars is,

$$
\frac{S_{t}}{F_{t}}\left(1+i_{t}^{\text {Euro }}\right)
$$

- Trade B: Invest in a one-period bond in US dollars at riskless interest rate $i_{t}^{U S D}$ to receive $1+i_{t}^{U S D}$ at date $t+1$

Trade A and Trade B both invest one dollar at time $t$ for return at time $t+1$. Thus we may expect that,

$$
\frac{S_{t}}{F_{t}}\left(1+i_{t}^{\text {Euro }}\right)=1+i_{t}^{U S D}
$$

In fact, while this relation held almost exactly prior to 2008 (based on LIBOR for the two interest rates), during the crisis and beyond, the pattern has been that,

$$
C I P_{t}^{\text {Deviation }} \equiv \frac{S_{t}}{F_{t}}\left(1+i_{t}^{\text {Euro }}\right)-1+i_{t}^{U S D}>0
$$

As Ivashina et al. [2015] document, during the financial crisis, a number of European borrowers lost access to US dollar short-term money market funding. They were unable to rollover dollar loans. One way they dealt with this dollar liquidity squeeze was to borrow Euros and convert the Euros into dollars, while hedging the repayment in the forward market. That is, they took the opposite side of Trade A.

Typically, a US bank took the other side and hence needed to absorb an increasing quantity of trade A. In terms of the model, the supply of asset A, $\theta_{A}$, increased (or $\rho_{S}$ increased). As a result, and given intermediation frictions, the return on trade A rose relative to that of trade $\mathrm{B}$ as frictions worsened in the crisis. The pattern is evident in Figure 3 where we plot the CIP deviation (also referred to as the "basis") for the Euro relative to the US and the Yen relative to the US. Notice that the CIP deviations widen in late 2008 and take many months to reverse, rather than days as may be expected with a market micro-structure friction.

We can understand these violations through the lens of intermediary asset pricing. The return to trade A corresponds to a more intermediated asset return than the return to 


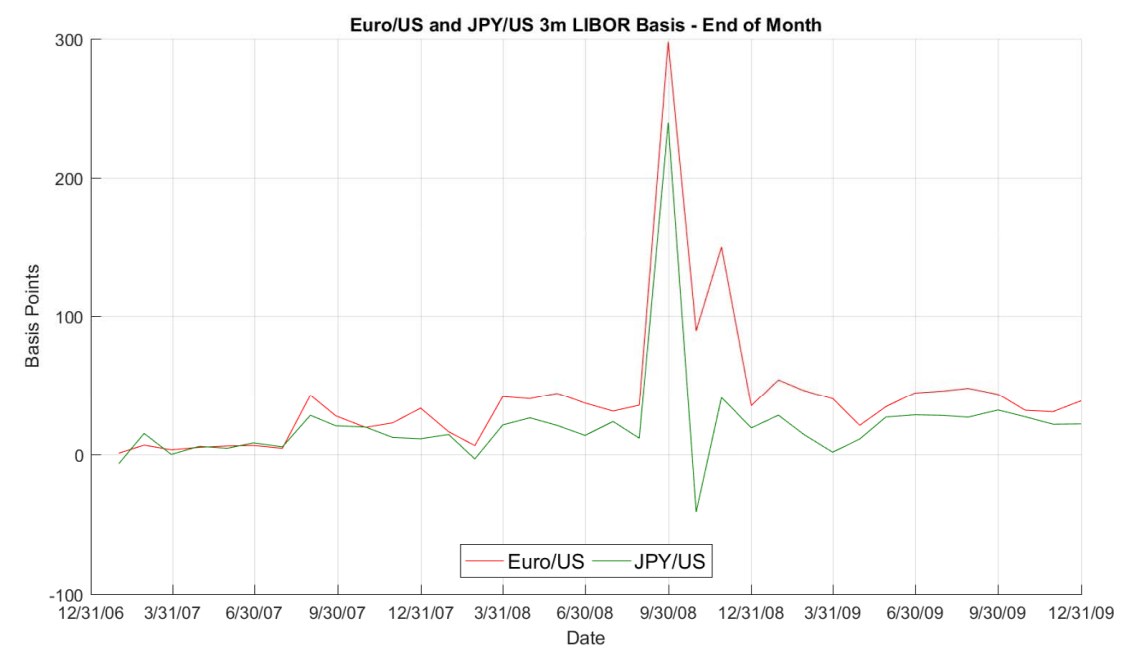

Figure 3: The Euro/US and JPY/US CIP Deviation are graphed from 2007 to 2009. The bases are positive and jump during the peak of the financial crisis. Sources: Datastream, FRED.

trade $\mathrm{B}$. This is a natural association because trade A involves a forward contract (i.e. the forward price $F_{t}$ ) that is written by a bank. Moreover, US households directly own trade $\mathrm{B}$ which is riskless investments in USD. So their SDF prices trade B. But trade A offers a higher return than trade B, implying their SDF does not price trade A. Figure 1 is evidence of intermediary pricing because as intermediation frictions worsen in the crisis, the relative return between trade $\mathrm{A}$ and $\mathrm{B}$ rose. If intermediation was frictionless, households would provide more capital to intermediaries to take advantage of the return spread, and drive the spread to zero.

Du et al. [2017] provide sharper evidence tying the movements in CIP deviations to capital frictions in intermediation. They note that capital requirements on some banks are based on a snapshot of their balance sheets at quarter-end. Banks thus face tighter capital requirements at quarter-ends relative to days before and after. They show that the CIP deviation widens on quarter-ends consistent with this capital tightness. Figure 4 graphs this pattern not for the USD/Euro but for the USD/Yen CIP deviation, which reflected the same economics. The graph is for a period from 2014 to 2016, well after the financial crisis, but still reflecting intermediation frictions. The CIP deviation jumps at quarter end consistent with the pattern of capital constraints. Moreover, the jump is largest for the 


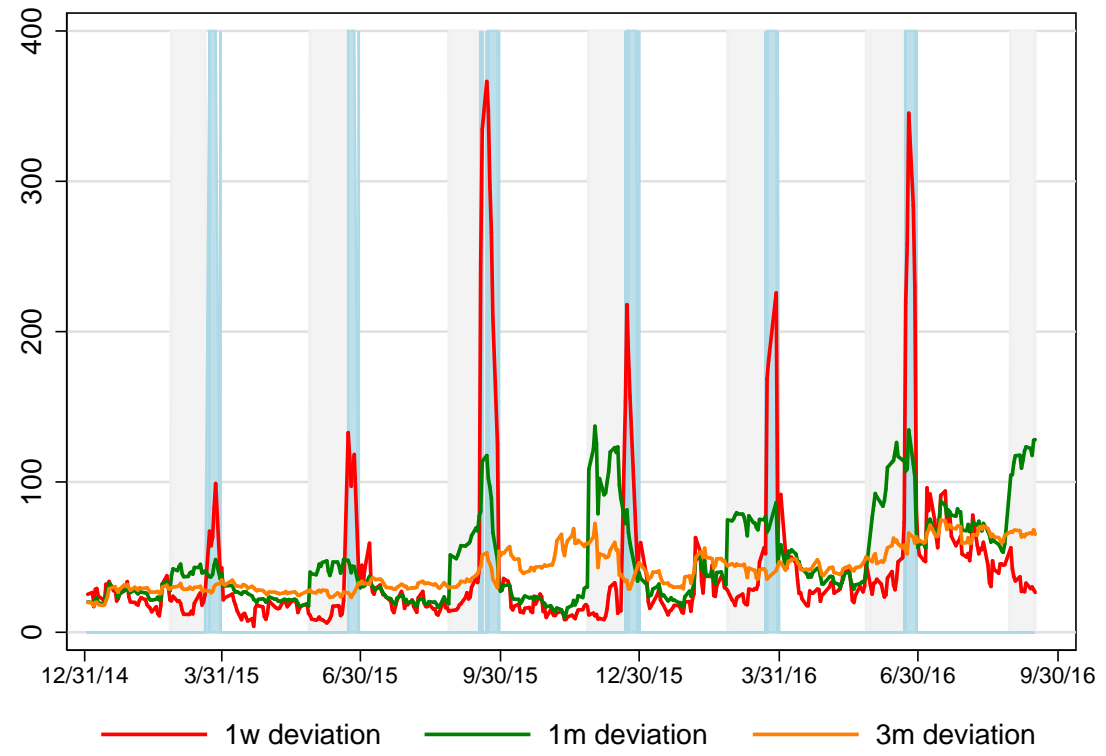

Figure 4: The CIP deviation for USD versus Yen is graphed for maturities of 1 week, 1 month, and 3 months. The vertical blue lines correspond to quarter ends. Source: Du et al. [2017].

shortest maturity one-week contract because this contract's term has the largest fraction $\left(\frac{1}{7}\right.$ th) for which the capital constraint is tight, as suggested by theory. It is hard to reconcile these patters with any theories involving household risk preferences, so that the evidence for intermediary asset pricing is quite strong.

\subsection{Insurance markets}

Some of the clearest evidence for capital effects in intermediary asset pricing comes from insurance markets. Froot and O'Connell [1999] study property and casualty insurance. They show that the price of such insurance is described by a cycle: a natural disaster results in reductions in the capital of insurers; the price of new policies rise and the quantity of insurance sold falls; as capital builds up, the prices fall and quantities rise. This is compelling evidence of shifts in the supply of insurance induced by capital shocks, because a nonintermediary asset pricing story would have to tie the cycle in insurance prices/quantities to a cycle in the probability of a natural disaster, which seems implausible. 
Koijen and Yogo [2015] study life insurers and their pricing of a long-term insurance policies during the financial crisis. They demonstrate a capital effect in the pricing of these policies, albeit in a counterintuitive manner. In contrast to Froot and O'Connell [1999] where insurance premium rises following an impairment of capital, Koijen and Yogo [2015] show that insurers sold policies at prices below actuarial fair value, and that this gap was larger for insurers facing tighter capital constraints. They show that this behavior is because sales of such insurance increase regulatory capital in the short-run.

The Koijen and Yogo [2015] evidence is consistent with the rest of the evidence for capital effects we have discussed in this section and thus reinforces support for theories of intermediary asset pricing. It goes beyond the other evidence in two ways, which are worth highlighting.

First, the market for retail insurance allows the econometrician to observe different transaction prices for the same asset, sold by different insurance companies and purchased by different households. In the forward exchange rate market, we observe only one price, the "best" price for the forward contract. This means we can only learn how shocks to capital impact the aggregate supply curve for forwards, which involves studying a single time series of capital shocks and forward prices. In the retail setting, given the search and attention frictions, each insurer has market power in selling contracts. Thus, we can learn about the supply curve for insurance at the insurer level, providing much more variation to study. Since the economics of capital effects remain the same, that is, capital shocks impact supply, the study has external validity beyond the retail insurance setting. For instance, Bao et al. [2017] document that the liquidity provision by dealers has been adversely affected by the regulatory tightening of the Volker rule in the context of corporate bonds traded in the Over-The-Counter (OTC) market.

Second, the rest of the studies we have described convincingly demonstrate a capital effect, but they stop short of quantifying the capital effect. Ultimately for model construction, it is necessary to know how a reduction of say $x \%$ in capital impacts supply. Koijen and Yogo [2015] take a structural approach to estimation, allowing them to quantify the capital effect. 


\section{Stochastic Discount Factor Methodology}

In the previous section, we discussed evidence in favor of the prediction that shocks to intermediary capital/constraints will explain movements in the prices of intermediated assets. We now discuss a second empirical literature that investigates how intermediary variables explain the expected returns on intermediated assets. This literature constructs a factor that is posited as a proxy for the intermediary SDF and examines its pricing power for intermediated asset classes. It likewise constructs a SDF for the household sector which in a frictionless (veil) world should also price these assets. The test of intermediary asset pricing relies on showing that the intermediary SDF can explain variation in asset returns while the household SDF cannot.

We discuss two papers in the literature, Gabaix et al. [2007] and He et al. [2017]. As we explain, these papers are less well identified than the papers discussed in the previous section, but the approach is particularly well suited for quantifying models of intermediary asset pricing. Both papers estimate an intermediary price of risk which can serve as targets to match in quantitative intermediary asset pricing models.

\subsection{Mortgage-backed securities market}

Gabaix et al. [2007] (GKV) study the pricing of prepayment risk in mortgage-backed securities (MBS), providing evidence to support intermediary asset pricing models. MBS securities rise and fall in value based on the exercise of homeowners' prepayment options. When a homeowner prepays a mortgage, the corresponding MBS is called back at par. Depending on the interest rate environment, unexpected prepayments can either hurt or benefit the MBS investor. For an MBS with a low coupon trading in an environment where market interest rates are high, unexpected prepayments benefit the MBS investor. In the opposite case, where the coupon is higher than market interest rates, unexpected prepayments hurt the MBS investor. GKV define prepayment risk as the risk of prepayment that are orthogonal to market interest rates (which investors are able to hedge out), and study the pricing of this prepayment risk.

Importantly, for an investor who specializes in the MBS market and therefore holds 
a concentrated portfolio of MBS, prepayment risk represents a risk to the value of his portfolio. GKV posit that financial intermediaries, such as mortgage funds, will hold such a concentrated portfolio and be exposed to prepayment risk. They derive an SDF of such an investor and empirically demonstrate that this SDF prices the cross-section and time series patterns in the spreads of MBS over Treasury bonds.

They also provide evidence that a household SDF does not price prepayment risk. They note that for every MBS investor who is short a prepayment option, there is a homeowner who is long the prepayment option, and hence prepayments do not cause changes to aggregate wealth or the aggregate endowment. Thus under a non-intermediary model the pricing of prepayment risk should refect the covariance of prepayment shocks with aggregate household wealth or consumption.

There are three principal empirical results in the paper. First, they show that in the cross-section, MBS with more prepayment risk (i.e., securities that fall in value when prepayments are unexpectedly high) carry a higher spread than those with lower prepayment risk. That is, prepayment risk carries a positive risk premium. Second, the observed covariance between prepayment risk and either aggregate wealth or consumption implies a sign that is opposite that required to match the observed prices of prepayment risk. Prepayments are modestly procyclical so that MBS securities that fall in value when prepayment shocks are high should carry a negative risk premium rather than positive risk premium. Last, they derive a proxy for the riskiness of the MBS market and show that the market price of prepayment risk comoves with this proxy.

Figure 5 presents the main result from the paper. For each month, the price of prepayment risk is estimated from the cross-section of MBS spreads. That is, the $\beta$ with respect to prepayment risk is estimated for each MBS, and the price of prepayment risk is then the spread compensation per unit of $\beta$. The time series of this price of prepayment risk is plotted in black. Theoretically, an investor who is long the entire portfolio of MBS will price prepayment risk depending on the investor's exposure to prepayment risk. If the market portfolio consists of MBS with higher coupons relative to the market interest rate, the unexpectedly faster prepayments result in larger losses to the investor. Thus the investor's exposure to prepayment risk will depend on the average coupon of the market portfolio of 


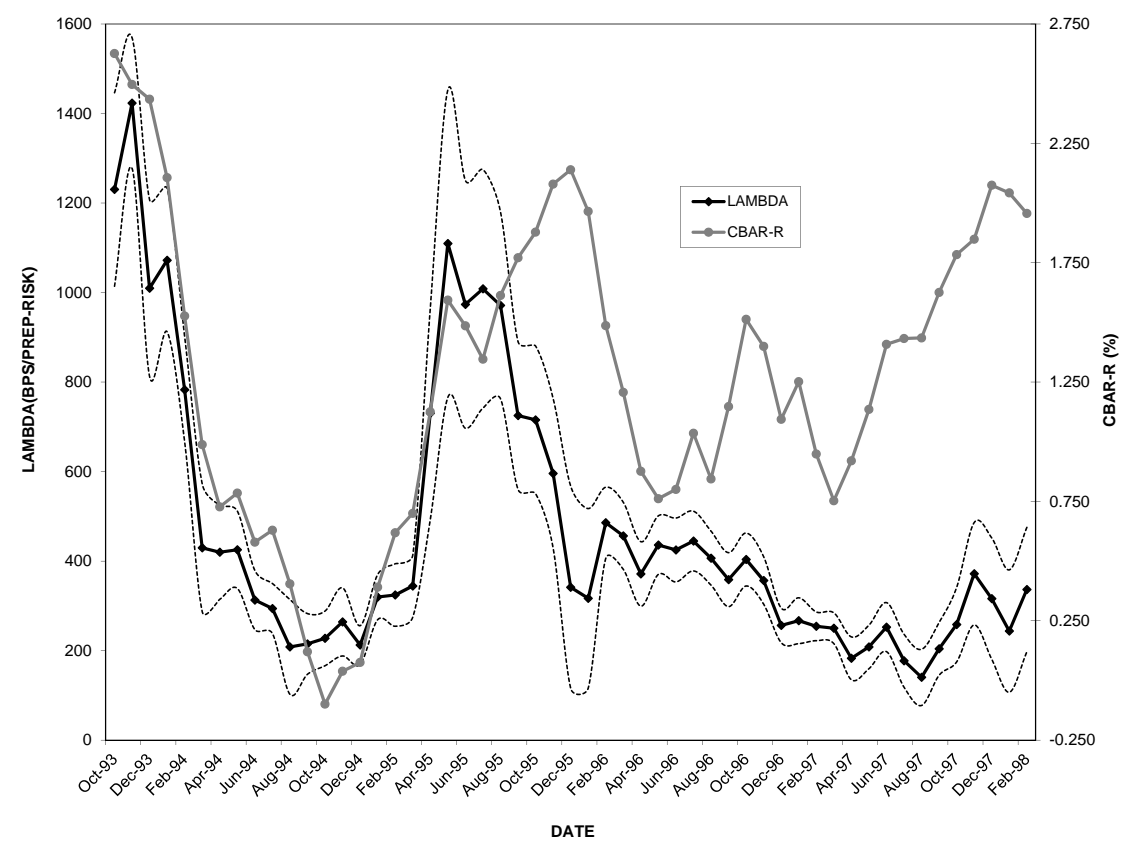

Figure 5: The estimated monthly market price of prepayment risk (LAMBDA) is plotted. The intermediary asset pricing implied price of risk, CBAR-R, is plotted for comparison. Here CBAR is the average coupon outstanding in the MBS market and R is the 10-year constant maturity Treasury (CMT) interest rate. Source: Gabaix et al. [2007]

MBS relative to riskless interest rates, or CBAR-R. The figure shows that the theoretical and estimated price of prepayment risk move together. Regression analysis reported in GKV confirm the pattern evident in the figure.

The empirical approach of GKV is to construct a theoretically derived intermediary SDF and show that this SDF prices MBS prepayment risk while a household based SDF does not price MBS risk. The approach is fruitful in this case because the object studied, prepayment risk, will carry opposite risk prices depending on the posited SDF. However, this statement rests on accurately measuring the household SDF. GKV use household consumption and aggregate wealth data to assess the household SDF.

Finally, we note that Gabaix et al. [2007] studies a small sample that ends in 1998. Recent papers such as Boyarchenko et al. [2017] and Diep et al. [2017] consider a longer sample and larger cross-section of MBS. Their results are also consistent with intermediary 
asset pricing in the MBS market.

\subsection{Broker/Dealer Capital}

He et al. [2017] (henceforth HKM) propose an empirical measure of the SDF of financial intermediaries based on broker/dealer capital ratio and explore its pricing power for seven asset classes, including equities, US government and corporate bonds, foreign sovereign bonds, options, credit default swaps (CDS), commodities, and foreign exchange (FX). The approach of confronting intermediary asset pricing theory with a broad set of asset classes is in contrast with Gabaix et al. [2007] who focus only on the highly specialized MBS market. HKM build on the seminal paper in this literature, Adrian et al. [2014], which uses broker-dealers' leverage rather than capital to measure the intermediary SDF. Adrian et al. [2014] explore the pricing power of broker-dealer leverage for equities and US government bonds, while HKM expand the approach to include more intermediated asset classes.

\subsubsection{Intermediary capital ratio}

HKM study primary dealers who serve as counterparties of the Federal Reserve Bank of New York ("NY Fed" henceforth) in its implementation of monetary policy. These dealers are large and sophisticated financial institutions that operate in virtually the entire universe of capital markets, and include the likes of Goldman Sachs, JP Morgan, and Deutsche Bank. It is natural to focus on these dealers because they are active (hence are marginal investors) in many asset markets, just like the intermediaries of the model with multiple assets analyzed in Section 2.7 to Section 2.9.

Following He and Krishnamurthy [2012, 2013] and Brunnermeier and Sannikov [2014], HKM postulate that these dealers' equity capital ratio is the key determinant of the intermediary's SDF. When the intermediary experiences a negative shock to its equity capital, say, due to an unexpected losses in MBS, its risk bearing capacity is impaired and its value from an extra dollar of equity capital rises. More specifically, HKM construct the intermediary capital ratio, denoted by $\eta_{t}$, as the aggregate value of market equity divided by aggregate market equity plus aggregate book debt of the banking holding companies of 
primary dealers active in quarter $t:^{6}$

$$
\eta_{t}=\frac{\sum_{i} \text { Market Equity }_{i, t}}{\sum_{i}\left(\text { Market Equity }_{i, t}+\text { Book Debt }_{i, t}\right)}
$$

In the language of the Intertemporal-CAPM model (Merton [1973]), the intermediary capital ratio $\eta_{t}$ is state variable that captures the soundness of the financial sector and hence matters for risk compensation, in addition to the aggregate market return $R_{t}^{W}$ which potentially capture other economy-wide shocks. Based on a parsimonious Intertemporal-CAPM style two-factor-structure consisting of the intermediary capital factor $\eta_{t}^{\Delta}$ (the percentage innovation to $\eta_{t}$ ) and the stock market return $R_{t}^{W}$, HKM empirically show that the intermediary capital factor has significant explanatory power for cross-sectional variation in expected returns in the seven asset classes mentioned.

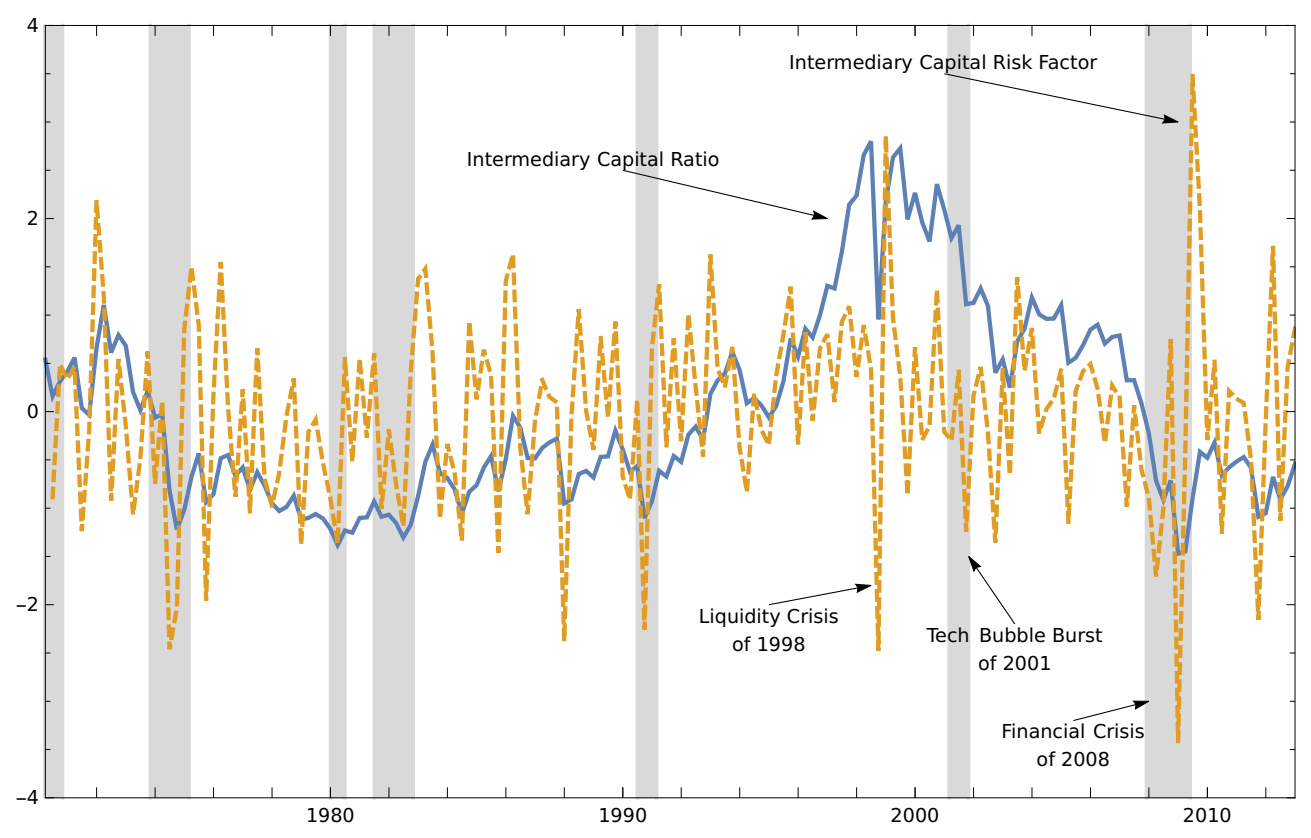

Figure 6: The figure graphs HKM's $\eta_{t}$ and $\eta_{t}^{\Delta}$ over the period from 1970Q1 to 2012Q4, along with NBER recessions as shaded areas. Source:He et al. [2017]

\footnotetext{
${ }^{6}$ Market values of equity arguably better reflect the financial distress of intermediaries. In the empirical corporate finance literature that studies the capital structure of nonfinancial firms [Leary and Roberts, 2005], book values of debt are used to approximately measure unobserved market values of debt. The approximation is more accurate in our context of financial firms, as for banking institutions the majority of their liabilities consist of safe short-term debt such as deposits, repurchase agreements (repo), and trading liabilities which are to a large extent collateralized and have market values equal to the face or book value.
} 
Figure 6 graphs $\eta_{t}$ and $\eta_{t}^{\Delta}$ over the period from 1970Q1 to 2012Q4 reported in HKM, along with NBER recessions as shaded areas. There are several noteworthy observations regarding the relation between $\eta_{t}^{\Delta}$ and business cycle macroeconomic conditions. The most negative shock to intermediary capital occurred during the 2008 financial crisis, which coincided with the Great Recession. Somewhat surprisingly, it is the liquidity crisis during the fall of 1998 that witnessed the second largest negative $\eta_{t}^{\Delta}$, an episode that coincided with turmoil in the options market but little action in the broad stock market. Last, despite a significant stock market crash (the Tech bubble burst) during the 2001 recession, we only observe a relatively modest negative drop in $\eta_{t}^{\Delta}$. These observations illustrate the difference between the fundamental shocks (as reflected by $R_{t}^{W}$ ) and financial shocks (as reflected by $\left.\eta_{t}^{\Delta}\right)^{7}$

\subsubsection{Price of intermediary capital risk}

As shown in Section 2.9, the standard risk-return relationship implies that any asset $j$ with a $\beta_{j}$ loading on the intermediary capital risk factor $\eta_{t}^{\Delta}$ should be compensated by an expected return of $\lambda_{\eta} \beta_{j}$ in equilibrium. Importantly, $\lambda_{\eta}$ is independent of the asset class, because the price of risk $\lambda_{\eta}$ should only be specific to the characteristics of the investor for whom we measure the SDF. For instance, in the asset pricing model analyzed in Section 2.9 , the price of risk is proportional to the relative risk aversion of the marginal investor (either managers or sophisticated investors) and the variance of their return on wealth. Asset classes with different degrees of intermediation (say equity versus CDS) might differ in their risk loadings to $\eta_{t}^{\Delta}$, so that some asset classes are more sensitive to intermediary capital shocks, but this heterogeneity should be reflected in the asset $\beta_{j}$ only.

HKM test this prediction. They first perform cross-sectional asset pricing tests within each class separately, i.e., obtaining betas of each asset $j$ in asset class $k$ from time-series regressions, then running a cross-sectional regression of average excess portfolio returns on

\footnotetext{
${ }^{7}$ Muir [2017] present more comprehensive evidence from a large international panel on the differential impact of financial and real shocks for asset prices. He compares recessions involving financial crises (e.g., bank runs, bank closures) to non-financial recessions with similar declines in aggregate consumption, and shows that the risk premia on stocks and corporate bonds rise substantially in the financial recessions relative to the non-financial recessions.
} 
the estimated betas. This procedure allows HKM to estimate the asset class-specific risk prices $\lambda_{\eta}^{k}$ for each asset-class $k{ }^{8}$ Theory suggests that these risk prices $\lambda_{\eta}^{k}$ should be positive and equal across asset classes, subject to estimation error. This is indeed what HKM find. Figure 7 plots intermediary risk prices from different asset classes, together with the $95 \%$ confidence intervals. As shown, their test rejects the null of a $0 \%$ risk price in all classes, but cannot reject the hypothesis that the estimated risk price is equal to $9 \%$ per quarter (the value found in the all portfolios case which pools all testing porfolios together) for any of the individual asset classes, at the $5 \%$ significance level.

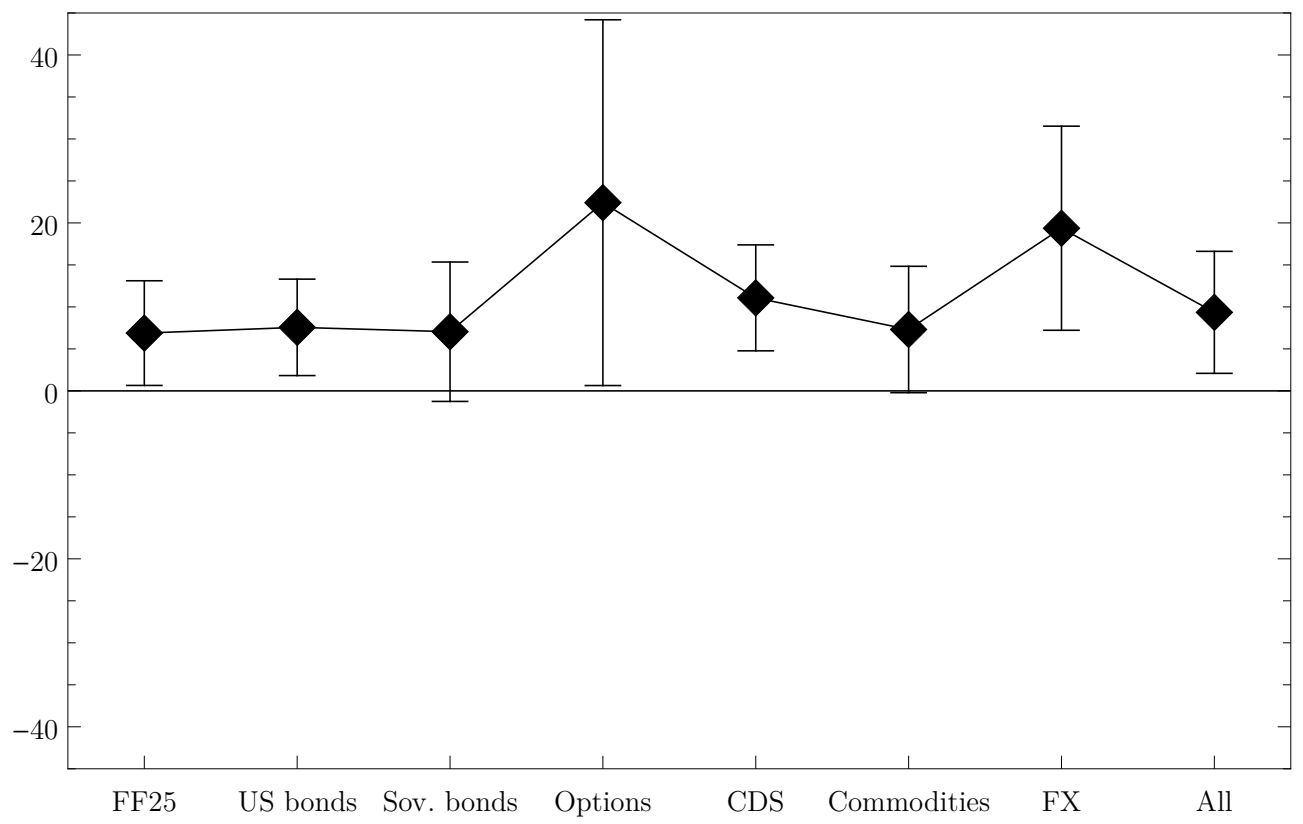

Figure 7: The figure plots intermediary risk prices from different asset classes, together with the $95 \%$ confidence intervals. Source: He et al. [2017]

Theoretically, the prediction of equal risk prices relies on the following assumptions. First, the proposed equity capital ratio (20) represents the intermediaries' marginal value of wealth. Second, intermediaries are active traders in all asset markets (though not necessarily with large net positions). Also implicit in these assumptions is a degree of homogeneity in the pricing kernels of individual financial intermediaries. That all financial intermedi-

\footnotetext{
${ }^{8}$ Recall that we have emphasized nonlinearity, i.e., the price of risk is state dependent and may rise during severe economic downturns. This is illustrated by GKV in Figure 5. Under the assumption of constant asset beta, the unconditional estimate obtained in HKM can be viewed as the average price of risk over time.
} 
aries are homogeneous is perhaps the most tenuous of these assumptions. Its failure could potentially explain the somewhat higher price of risk in options and FX point, for example, if intermediaries that specialize in trading these securities differ in substantial ways from other intermediaries [see, for example, Gârleanu et al., 2015].

\subsubsection{Necessary and sufficient for intermediary asset pricing?}

Still, in light of Proposition 3 in Section 2.9, Figure 7 showing that the intermediary's SDF has explanatory power for a wide range of asset classes is necessary but not sufficient to demonstrate the core of intermediary asset pricing, i.e., intermediaries are not a veil. To claim that, one needs to show that the households' SDF fails. Although there exist some papers aiming to explain the time-series behavior of index options under the rare-disaster consumption-based asset pricing framework (e.g., Barro and Liao [2016]), we are not aware of papers that successfully explain the cross-section of expected returns for the non-equity asset classes considered by HKM using an SDF constructed from household consumption data.

Another way of approaching the issues is to see what SDFs do not work in explaining returns. The model developed in Section 2 says that if all plausible SDFs work, then the intermediary is just a veil. HKM present two sets of results to reject the veil hypothesis. First, HKM show that the well-known factors commonly used in the literature, including the Fama-French five factors, momentum, and liquidity (Pástor and Stambaugh [2003]), perform poorly. If we interpret the earlier success of these factors as due to their capturing

the SDF of households in the equity market, this result shows that their SDF fails to price the non-equity-heavy asset portfolios in HKM. Furthermore, HKM postulate that within the broker-dealer sector, primary dealers, who are large and active in almost all asset markets, are the intermediaries of intermediary asset pricing models. The SDF of nonprimary dealers, who tend to be smaller, standalone, broker-dealers for the equity market but who trade little in derivatives markets, should not price the cross-section of returns. HKM repeat their main asset pricing test using the equity capital ratio constructed from non-primary dealers. The SDF works for equity portfolios but not for other asset classes 
(Table 7 Panel A in HKM). This result may imply that non-primary dealers are a veil whose trades reflect the preferences and tastes of households. The fact that these other constructed factors fail to price the assets studied in HKM while the primary-dealer equitycapital ratio does, is the strongest evidence presented by HKM in favor of intermediary asset pricing. ${ }^{9}$

\section{Summary and Conclusion}

We have explained both the theory behind intermediary asset pricing as well as some of the empirical approaches taken to testing the theory. There is now a large body of work in this area. On the theory side the basic groundwork for intermediary asset pricing has been laid out. On the empirical side, there are a number of papers that have demonstrated intermediary asset pricing effects along the lines that we covered in Section 3. There is a smaller but growing body of literature that tries to construct an intermediary stochastic discount factor.

We close with a short wish-list for future work in this area. For empirical work: What are the most salient financial frictions driving intermediary asset pricing? Which class of intermediaries are most prominent for understanding asset prices? How much does heterogeneity within the intermediary sector matter? What is the relation between intermediary risk prices as measured from asset prices and macroeconomic activities such as corporate and residential investment? For theoretical work: We need to construct tractable models to replicate the empirical findings both qualitatively and quantitatively. These models need to be embedded within a macroeconomic framework to elucidate links between the financial sector, asset prices, households, and the real sector. Finally, these models need to be quantitative in nature in order to evaluate policy counterfactuals that can guide financial regulation.

\footnotetext{
${ }^{9}$ Note that this evidence also differentiates intermediary asset pricing from heterogeneous agent frictionless models such as Dumas [1989]. In that frictionless model, the pricing kernel of any agent should price all assets, and there is no particular reason why the SDF derived from primary dealers will perform better than that of any other.
} 


\section{References}

Andrew B. Abel, Janice C. Eberly, and Stavros Panageas. Optimal inattention to the stock market with information costs and transactions costs. Econometrica, 81(4):1455-1481, 2013.

Tobias Adrian, Erkko Etula, and Tyler Muir. Financial intermediaries and the cross-section of asset returns. Journal of Finance, 69(6):2557-2596, 2014.

Franklin Allen. Presidential address: Do financial institutions matter? Journal of Finance, 56(4):1165-1175, 2001.

Franklin Allen and Douglas Gale. Limited market participation and volatility of asset prices. The American Economic Review, pages 933-955, 1994.

Franklin Allen and Douglas Gale. Optimal financial crises. The journal of finance, 53(4): 1245-1284, 1998.

Yakov Amihud, Haim Mendelson, and Lasse Heje Pedersen. Market liquidity: asset pricing, risk, and crises. Cambridge University Press, 2012.

Jack Bao, Maureen O'Hara, and Xing (Alex) Zhou. The volcker rule and market-making in times of stress. Technical report, 2017.

Robert Barro and Gordon Y. Liao. Options-pricing formula with disaster risk. Technical report, 2016.

Nina Boyarchenko, Andreas Fuster, and David O. Lucca. Understanding mortgage spreads. FRB NY Working Paper, 2017.

Markus K. Brunnermeier and Yuliy Sannikov. A macroeconomic model with a financial sector. American Economic Review, 104(2):379-421, 2014. doi: 10.1257/aer.104.2.379.

Markus K. Brunnermeier, Thomas Eisenbach, and Yuliy Sannikov. Macroeconomics with Financial Frictions: A Survey. Cambridge University Press, New York, 2013. 
Peter Diep, Andrea Eisfeldt, and Scott Richardson. Prepayment risk and expected mortgage-backed security returns. Working Paper, 2017.

Wenxin Du, Alexander Tepper, and Adrien Verdelhan. Deviations from covered interest rate parity. 2017.

Darrell Duffie. Asset price dynamics with slow-moving capital. Journal of Finance, 65(4): 1237-1267, 2010.

Bernard Dumas. Two-person dynamic equilibrium in the capital market. The Review of Financial Studies, 2(2):157-188, 1989. doi: 10.1093/rfs/2.2.157.

Eugene F. Fama. Banking in the theory of finance. Journal of Monetary Economics, 6(1): $39-57,1980$.

Kenneth A Froot and Paul GJ O'Connell. The pricing of us catastrophe reinsurance. In Kenneth A Froot, editor, The Financing of Catastrophe Risk, pages 195-232. University of Chicago Press, 1999.

Xavier Gabaix, Arvind Krishnamurthy, and Olivier Vigneron. Limits of arbitrage: Theory and evidence from the mortgage-backed securities market. Journal of Finance, 62(2): $557-595,2007$.

Nicolae Gârleanu, Stavros Panageas, and Jianfeng Yu. Financial entanglement: A theory of incomplete integration, leverage, crashes, and contagion. American Economic Review, 105:1979-2010, 2015.

Valentin Haddad and Tyle Muir. Do intermediaries matter for aggregate asset prices? Ucla working paper, 2017.

Zhiguo He and Arvind Krishnamurthy. A model of capital and crises. The Review of Economic Studies, 79(2):735-777, 2012. doi: 10.1093/restud/rdr036.

Zhiguo He and Arvind Krishnamurthy. Intermediary asset pricing. American Economic Review, 103(2):732-770, 2013. 
Zhiguo He, Bryan Kelly, and Asaf Manela. Intermediary asset pricing: New evidence from many asset classes. Journal of Financial Economics, 126(1):1-35, 2017.

Victoria Ivashina, David S Scharfstein, and Jeremy C Stein. Dollar funding and the lending behavior of global banks. The Quarterly Journal of Economics, 130(3):1241-1281, 2015.

Ravi Jagannathan and Yong Wang. Lazy investors, discretionary consumption, and the cross-section of stock returns. The Journal of Finance, 62(4):1623-1661, 2007.

Ralph S.J. Koijen and Motohiro Yogo. The cost of financial frictions for life insurers. American Economic Review, 105:445-475, 2015.

Arvind Krishnamurthy. How debt markets have malfunctioned in the crisis. Journal of Economic Perspectives, 24(1):3-28, March 2010. doi: 10.1257/jep.24.1.3.

Mark T. Leary and Michael R. Roberts. Do firms rebalance their capital structures? Journal of Finance, 60(6):2575-2619, 2005. ISSN 1540-6261. doi: 10.1111/j.1540-6261.2005. 00811.x.

Robert Merton. An intertemporal capital asset pricing model. Econometrica, 41(5):867-87, 1973.

Mark Mitchell and Todd Pulvino. Arbitrage crashes and the speed of capital. Journal of Financial Economics, 104(3):469-490, 2012.

Mark Mitchell, Lasse Heje Pedersen, and Todd Pulvino. Slow moving capital. American Economic Review, 97(2):215-220, May 2007. doi: 10.1257/aer.97.2.215.

Tyler Muir. Financial crises and risk premia. Quarterly Journal of Economics, 132:765-809, 2017.

L’uboš Pástor and Robert F Stambaugh. Liquidity risk and expected stock returns. Journal of Political Economy, 111(3):642-685, 2003.

Jiang Wang. The term structure of interest rates in a pure exchange economy with heterogeneous investors. Journal of Financial Economics, 41(1):75 - 110, 1996. 